consciousness, as well as collective consciousness and public opinion. The development of problems of mass consciousness in the Soviet scientific literature was hindered by the fact that it was considered as an attribute of mass society and as an alternative to class-consciousness. The problem of layers and fields of mass consciousness and its historical types has not been properly investigated yet.

Keywords: mass consciousness, mass, mass activity, collective consciousness, collective unconscious, ordinary consciousness, public opinion, mass society, public consciousness

ОГАНИСьЯН Юлий Степанович - доктор исторических наук, профессор; главный научный сотрудник Института социологии ФНИСЦ РАН (117218, Россия, г. Москва, ул. Кржижановского, 24/35, кopn. 5; dorunat@gmail.com)

\title{
ПОСТСОВЕТСКИЙ ЛИБЕРАЛИЗМ: ОТ РЕФОРМЫ К РЕВОЛЮЦИИ?
}

\begin{abstract}
Аннотация. Автор анализирует феномен радикализации социально-политических взглядов идеологов постсоветского либерализма, которые, апеллируя к протестным настроениям масс, формируют идеи назревания новой - «антипутинской» - революции в России. Основываясь на данных социологических исследований, автор доказывает несостоятельность утверждений о наличии предреволюционной ситуации в стране, допуская вместе с тем возможность дестабилизации социально-политической обстановки при соединении радикал-либеральных идей с массовым протестным движением и внешней поддержкой несистемной оппозиции.
\end{abstract}

Ключевые слова: либерал-реформизм, революционная ситуация, социальное неравенство, несистемная оппозиция, протестное движение

$\Pi$ ризрак революции вновь обживает медийное пространство России, образуемое сетевыми структурами Интернета, телевидения, печати, становится актуальным предметом социально-политического дискурса. Что же это означает? Предвестие новой революции? Реальную угрозу великих потрясений, каковые страна неоднократно переживала в XX в.? Еще недавно казалось, что эта угроза навсегда осталась в прошлом. В общественном сознании укреплялось убеждение, что эпоха социальных катастроф в истории страны завершилась развалом Советского Союза, что «либеральная революция» 1990-х гг. вывела страну на путь мирного развития и демократических реформ. По данным социологических опросов начала нулевых годов, само понятие «революция» на ассоциативном уровне воспринималось позитивно лишь $11 \%$ россиян, негативно - 47\%, нейтрально - 42\% [Российское общество... 2016: 218].

Озадачивает то, что социальным источником алармистских и призывающих к революции сигналов служат не массовые настроения, а узкогрупповые устремления элитарной прослойки общества, интересы которой выражает несистемная либеральная оппозиция, традиционно чуждая всякому революционаризму. Так, историк, заместитель председателя Партии народной свободы (ПАРНАС) А.Б. Зубов утверждает, что антисоветский переворот 1990-х гг. был всего лишь неудавшимся «либеральным экспериментом», завершившимся предпринятой В.В. Путиным попыткой «рекоммунизации», противодействие которой требует сплочения демократических сил общества ${ }^{1}$.

\footnotetext{
1 «Это был переворот, поставивший крест на свободной России, и он не убран до сих пор»: историк Андрей Зубов о революции 1917-го. - Настоящее время. 05.11.2017. Доступ: https://www. currenttime.tv/a/28830828.html (проверено 04.03.2020).
} 
Более того, по убеждению профессора городского университета Нью-Йорка А. Янова, революция уже разворачивается, а митинг в Москве 24 декабря 2011 г. стал «девятым валом» начального этапа этой революции. Повышая уровень значения данного события до исторического и общеевропейского, профессор сопоставляет его с революциями 1848 г. в Европе и 1905 г. в России ${ }^{1}$.

Поток подобных суждений нескончаем. Налицо всплеск предреволюционного алармизма. Есть ли для этого убедительные основания? Является ли угроза революции продуктом реальных социальных процессов или всего лишь плодом воображения экстремистских противников режима?

Бесспорно, не может не вызывать тревоги явный рост протестных настроений в российском обществе, вызванный падением жизненного уровня широких масс населения, углублением социального неравенства, повальной коррумпированностью госаппарата, нерешенными жилищными, экологическими проблемами, другими такого рода факторами, негативные действия которых на граждан обостряет официальная пропаганда уверениями, что их жизнь становится все лучше, и популистскими посулами власти, не заслуживающими доверия.

Возникает ряд вопросов общесоциального характера. Почему либералам удалось в считанные годы развалить Советский Союз и покончить с социализмом в России? В чем социальный смысл «либеральной революции» конца XX в., и почему либералы хотят продолжить ее в новых условиях? Что, наконец, побудило В.В. Путина отступиться от либеральной идеи, которая в свое время привела его к руководству страной, заявив в интервью Financial Times в июне 2019 г., что она «просто изжила себя окончательно»?

Ответы на эти вопросы следует, видимо, искать вне политической конъюнктуры и идеологических пристрастий - в широком социально-историческом контексте, минуя те социологические трактовки истории, которые коренятся в догматах «научного коммунизма».

Триумф постсоветского либерализма объясняется не только разложением правящей элиты, ее неспособностью адекватно ответить на социальные ожидания народа, отсутствием в результате массовой поддержки населения либо «происками мирового империализма». Скоротечная смена общественно-экономических формаций была обусловлена более существенным фактором объективного порядка - до поры скрываемым догмами «научного коммунизма» реальным, жизнеспособным потенциалом реанимации капитализма, а именно системой государственной собственности, которая наделяла государство, по существу, капиталистическими функциями управления народным хозяйством. Роль господствующего класса в такой системе выполняет высшая партийнохозяйственная номенклатура: партийные функционеры, крупные госчиновники, директора предприятий и т.п. Остальная масса населения служит неисчерпаемым резервуаром дешевого наемного труда, необходимого для форсированной модернизации страны.

Открытый Октябрем процесс социальных перемен, по существу, был направлен не на ликвидацию капитализма, а на преобразование его в капитализм государственный путем модернизации на новых социально-политических основах и под централизованным управлением партии и государства. Заключенные в нем потенции реставрации прежнего строя и реализовались в ходе либеральных реформ на пороге XXI в. в условиях кризиса советской системы, освободившего

1 Янов А. Мятеж или революция? - SNOB. 30.10.2015. Доступ: https://snob.ru/profile/11778/ blog/100062 (проверено 04.03.2020). 
госкапитализм от идеологических облицовок и обратившего общенародную собственность в частнокапиталистическую.

Радикальная смена общественного строя по своим катастрофическим последствиям вполне сопоставима с Октябрьской революцией. Это, конечно, революция, но, ясно, не та, которую можно встроить в ряд революций, признанных в историографии великими. Постсоветские катаклизмы, правомерно сравниваемые с послеоктябрьскими, вызваны вовсе не взрывом социальной энергии масс либо провидческими дерзаниями реформаторов, уловивших ее импульсы, что характерно для всех подлинно великих революций, а латентными процессами гниения правящей элиты. Перераспределение собственности и власти произошло одномоментно. Но кем? Как? В пользу кого? Окончательно ли? Снова напрашивается сравнение с Октябрем, от чего не уйдешь, пытаясь осмыслить реальности и фантасмагории постсоветизма, а также связанные с ними возможности новой либеральной революции.

В XX в. либералы дважды ввязывались в революционный процесс, ставя под угрозу само существование России как великой державы. В 1917 г. процесс, вызванный либеральной Февральской революцией, завершился захватом власти большевиками и установлением ими тоталитарного режима, который при всех его пороках и преступлениях сумел сохранить Россию как мировую державу. В конце столетия «либеральная революция» привела к власти в стране одержимых рыночной идеей реформаторов, которые, подобно иным временщикам в истории России, принялись куражиться над страной, испытывая терпение ее народа сперва «шоковой терапией», грандиозными аферами с ваучерами и залоговыми аукционами, а затем социально конфликтогенными экспериментами вроде монетизации льгот или повышения пенсионного возраста.

Такого рода «социальная» политика, собственно, и стимулировала радикализацию масс, все еще далекую, однако, от того порога, за которым возникает революционная ситуация. По массовости и остроте проявлений она несопоставима, к примеру, с антиправительственными выступлениями 2018-2019 гг. «желтых жилетов» во Франции и протестными движениями в других странах и является нормальным признаком растущей роли масс в ходе демократизации общественной жизни.

Но вопреки этому угроза революции продолжает обсуждаться либералами. Странно и то, что их традиционные требования структурных реформ, обеспечения гражданских свобод, справедливых выборов и т.П. мотивируются теперь несвойственными им прежде социальными аргументами, связанными с повышением уровня жизни, расширением прав трудящихся, ликвидацией нищеты.

Новое слово в развитии либеральной мысли? Постсоветский продукт социаллиберализма? Во всяком случае, именно в таком ключе рассматривается вероятность созревания революционной ситуации в России. К примеру, либеральный экономист, бывший министр финансов, а ныне глава Счетной палаты А. Кудрин предупреждал летом 2019 г. о реальной возможности социального взрыва, «если уровень бедности не замедлит рост».

Недоумение вызывает и то, что либералы выступили за революционный слом фактически собственного режима, возникшего и утвердившегося благодаря либеральным реформам, которые объективно не могли породить никакой иной формы власти. Социально-экономический блок правительства следует прежним - либерал-реформистским - курсом, и его реализуют соратники и ученики тех, кто инициировал и проводил асоциальную политику в 90-е гг. По всей видимости, эти последние, оттесненные В.В. Путиным от прямого участия в управлении делами государства, и образовали радикальное течение неолибера- 
лизма. Похоже, что именно данные обстоятельства и мотивировали путинскую критику либеральной идеи.

Кстати, еще в 1918 г. Н.А. Бердяев отмечал, что либерализм совершенно чужд интересам масс, целям их революционного освобождения, поскольку не выходит за пределы свободы личности, тогда как «революционный пафос» масс движим идеями равенства [Бердяев 1990: 150].

Либерализм никогда не был единым политическим движением. При обсуждении темы «Либералы и революция» на одном из круглых столов, организованном фондом «Либеральная миссия», историк В. Шелохаев отмечал, что либерализм России всегда был дифференцирован и фрагментирован. Сейчас, как и в прошлом, перед ним стоит задача создать единый фронт оппозиционного движения.

Еще дореволюционный идеолог либерализма Б.Н. Чичерин подразделял его на «оппозиционный», который систематически становится в оппозицию и не ищет достижения каких-либо положительных результатов, а «наслаждается самим блеском оппозиционного положения», и «охранительный», основанный на положительных началах и постоянно приноравливающийся к жизни, опирающийся на историю, понимающий условия власти и поэтому не становящийся к ней в «систематически враждебные отношения» [Попова 2006].

В отечественной историографии выделяются различные виды либерализма: консервативный, самодержавный, бюрократический, правительственный, соборный, а к либералам, соответственно, относились просвещенные монархи, их министры, губернаторы и т.д. Этот ряд дополнили послесталинские генсеки и президенты, каковые, понятно, по сравнению с «отцом народа» представлялись немыслимыми либералами.

Оставляя в стороне проблему классификации либералов, отметим, что российский либерализм как общественное течение в борьбе против феодальнокрепостнических порядков, за свободу личности, мысли и слова, за гражданские права, несомненно, сыграл исключительно важную роль в демократическом обновлении страны на всех этапах ее новейшей истории. По мнению философа А. Ахиезера, либерализм является совершенно необходимым элементом всякой власти в России. «Даже большевики, - отмечал он, - на протяжении 70 лет своей власти постоянно каплями впускали либерализм, и в результате либералы всего XX в. расплачиваются за грехи всей истории России».

Возразим: не во всех грехах и не всех либералов, а тех только и лишь за то, что, изменяя своим изначальным принципам, своей миссии вольнолюбцев, они поддались порче, которая, по Бердяеву, «началась со смешения целей и средств, с подмены духовных целей жизни материальными средствами». Вот и А.Б. Чубайс, один из инициаторов упомянутых выше афер, не так давно публично выразил обиду на российское общество за то, что оно по достоинству не оценило эти благодеяния либералов. Стоит ли удивляться в связи с этим тому, что само понятие «либерализм» стало одиозным, компрометирующим.

Меняя свои взгляды и принципы в зависимости от политической конъюнктуры, либерал легко перевоплощается в большевика, в националиста, в защитника или врага существующего режима, может стать, по мнению лидера кадетов П.Н. Милюкова, и революционером, разумеется, «при известных обстоятельствах» [Милюков 1930: 348].

В борьбе за власть либералы, утрачивая свою идентичность, обращаются в беспринципных политиканов, бездушных бюрократов, зачастую - в сановных коррупционеров, которых режим стал иногда упрятывать за решетку. Может быть, не всех, кто этого заслуживает? Может, власть слишком мягка и тем самым 
дает либеральной оппозиции еще один повод для ее свержения? Но стоит ли для этого совершать новую революцию?

Сомнение на этот счет выразил в одном из интервью экономист Е.Г. Ясин, министр в правительстве Е.Т. Гайдара, а ныне научный руководитель Высшей школы экономики: «Можно, конечно, взять и устроить революцию: этих скинуть, тех поставить, но вы что думаете, сразу все поменяется к лучшему? Я в это не верю. Основные революционные изменения позади, если вы не заметили, и они уже состоялись в 90 -е»1.

Это точка зрения, существенно отличная от позиции тех либералов, которые устрашают общество угрозами новой революции. Ее возможный исход фатально неизбежен: очередная историческая катастрофа, чреватая развалом государства, если, конечно, его не предотвратит режим авторитарного типа, более жесткий, чем нынешний.

Оправдан ли риск такого рода? Почему столь неустойчива идеологическая идентичность либеральной элиты? Дело, по-видимому, в том, что постсоветский либерализм не каноничен, не имеет собственной исторической традиции, чужероден либерализму классическому, дореволюционному. Его идентичность симулятивна, она всего лишь камуфляж идентичности подлинной и сформирована деградировавшей идеологией коммунизма, ибо фактически вся правящая элита федерального и регионального уровней вышла из партийно-государственной и комсомольской номенклатуры, сменив былые лозунги на либеральные мантры о свободе личности и общечеловеческих ценностях.

Хотя государственный переворот 90-х гг. и привел к смене социальных укладов, он произошел по модели, близкой к той, которую являют «цветные революции» последних десятилетий. Это была революция сверху, затеянная реформаторами, которые не имели адекватного представления о тенденциях и перспективах мирового развития и потому не смогли ни сформулировать, ни реализовать альтернативу, соответствующую социальным реалиям конца XX в., не понимая, откуда и куда ведут страну. Увязнув в догматических трактовках проблем социального развития, усвоенных в советских вузах, они рассматривали смену общественных формаций в парадигмах XIX в., хотя понятия «капитализм» и «социализм» давно утратили свой изначальный смысл. Перед реформаторами объективно стоял выбор не между зафиксированными марксизмом общественными формациями, а между рыночным социализмом и преобразованной под его влиянием иной социальной системой. Либералы предпочли вариант, обозначенный марксизмом-ленинизмом. В результате страна оказалась во власти пещерного, дикого капитализма, который на целую эпоху отстает от интенсивно развивающегося ныне посткапитализма и на такую же дистанцию - от рыночного социализма. В этом смысле реформистские поиски либералов, как и коммунистов, по сути дела, обращены в прошлое. По замечанию профессора Уорикского университета Колина Крауча, они являют собой «причудливую пару», ушедшую «в прошлое, которое сегодня представляется фантазией» [Крауч 2012: 15].

В отличие от российских реформаторов, китайские построили рыночный социализм. Китай стал экономической сверхдержавой, хотя его исходные позиции были гораздо слабее, чем у СССР, который имел более высокий уровень экономического развития и, как отмечалось выше, фактически готовые к рыночной перестройке народного хозяйства механизмы государственного капитализма. Но в ходе «либеральной революции» в России произошла не

1 Ясин Е.Г. Революция, если вы не заметили, уже состоялась: интервью. - Новая газета. 22.12.2017. № 143. Доступ: https://www.novayagazeta.ru/articles/2017/12/22/75010 (проверено 04.03.2020). 
перестройка социально-экономических отношений социализма на рыночной основе, а реставрация капитализма образца XIX в.

Проведенная сверху фактически насильственными методами приватизация, обрушив прежний социально-правовой порядок, инициировала становление капитализма симулятивного типа - социально-экономической конструкции, составленной из мутирующих обломков социализма, рыночных новаций по заимствованной модели монетаристской школы экономики, легализированных объектов теневой экономики. Сформировавшийся в результате социум иерархичен по своей структуре. Это, по характеристике академика М.К. Горшкова, «структура неравных социальных позиций индивидов, групп, классов в социальной иерархии» [Свобода. Неравенство. Братство... 2007: 6].

Становление нового социума сопровождалось углублением социального неравенства. По данным социологических исследований, перестроечные и последующие либеральные реформы к началу XXI в. привели к обнищанию большинства населения страны: до $70 \%$ россиян обретались в условиях нищеты, бедности или близких к этим условиях. Спустя десятилетие положение несколько улучшилось. Однако все еще более трети населения России жили за порогом или на грани бедности, а 7\% - в глубокой нищете, $17 \%$ населения пребывали в состоянии постоянного риска бедности [Социальные неравенства... 2008: 178-179]. Исследования социологов в 2017 г. показали, что «зона субъективного благополучия» охватывает всего лишь 24\% населения страны. Пропасть между бедными и богатыми увеличивалась и в кризисные годы. В 2017 г. на 10\% самых богатых приходилось $77,4 \%$, а на $1 \%$ самых богатых - 56\% объема всех частных богатств. Социальные контрасты углубляет государственный сектор экономики: руководители государственных корпораций в 2017 г. декларировали доходы в размере 250 млн руб., что в 662 раза превышает годовой среднедушевой денежный доход, составивший 377700 руб. Значительную часть российской бедноты составляют пенсионеры. Средний размер пенсии по старости составляет $32 \%$ средней заработной платы, и если не произойдут позитивные изменения в пенсионной системе, то, по прогнозам социологов, к 2024 г. это соотношение снизится до 27\% [Двадцать пять лет... 2018: 324]. В совокупности эти данные свидетельствуют о том, что разрушенная советская система социальной защиты все еще не замещена равной ей по эффективности системой, что углубляет социальные противоречия, которые в известных обстоятельствах могут обостриться до состояния, чреватого революционной ситуацией.

Сможет ли предотвратить развитие событий в этом направлении реализация майского указа президента 2018 г., который предусматривает к 2024 г. вдвое сократить число бедных, значительно улучшить жилищные условия и медицинское обслуживание населения, повысить средний возраст жизни и осуществить другие меры социальной защиты? Сомнительно. Решение этих задач не затрагивает базовые принципы социально-экономической политики, которые остаются такими же, какими сформировались в 1990-е гг., доказывая тем самым, вопреки приведенной выше оценке В.В. Путина, жизнеспособность либеральной идеи. Эти принципы - распределение национального дохода в интересах олигархического капитала, доминирование исполнительной власти в управлении народным хозяйством, сращивание административно-бюрократического аппарата с бизнесом путем создания коррупционных схем - по-прежнему определяют социально-политический курс правительства, порождая социальную напряженность в стране и стимулируя радикализацию внепарламентской оппозиции.

По мнению социолога Д. Сергеева, очередная либеральная революция скорей всего будет представлять собой столкновение интересов среднего класса с инте- 
ресами чиновничества, поскольку основная масса населения России всегда отторгала либеральные идеи. Чтобы она усвоила либерализм, пишет он, его необходимо трансформировать в модель, близкую к рыночному социализму; если либеральная власть не сможет таким образом решить основные социальные задачи, то движение в сторону революции продолжится - перспектива, которая требует широкого обсуждения в средствах массовой информации «от Интернета до вечерних телешоу» [Сергеев 2013].

Являются ли симптомами предреволюционной ситуации происходящие в Москве и других регионах страны многочисленные акты протеста - демонстрации, митинги, пикеты и т.п., вызванные повышением пенсионного возраста, ростом розничных цен и жилищных тарифов, «мусорной реформой», общим снижением уровня жизни населения? Едва ли. Во всяком случае, к ним не применима ленинская формула наличия революционной ситуации: «Низы не хотят, а верхи не могут жить по-старому». Низы все еще приемлют и одобряют существующий режим, свидетельством чему служат президентские, парламентские и прочие выборы, общие результаты которых неизменно совпадают с интересами правящих элит. Показательно и то, что, судя по опросам россиян, возможность «революционной» смены власти считают допустимой лишь $3 \%$ опрошенных, в принципе приемлют эту возможность 15\%, что показывает призрачность революционной перспективы для России [Российское общество... 2016: 233]. Верхи пока справляются с возникающими проблемами, сохраняя относительно стабильное положение в стране и не прибегая к таким чрезвычайным мерам, какие используют в аналогичных ситуациях правительства других стран. Однако нельзя исключать возможность того, что соединение радикаллиберальных идей с массовым протестным движением может дестабилизировать социально-политическое положение в стране.

Российские радикал-либералы в действительности и не помышляют о социальной революции, взламывающей общественный строй и открывающей путь принципиально иному социальному устройству. Строго говоря, речь идет о переделе власти и собственности. Историческая востребованность социальных революций, вовлекающих в борьбу огромные массы людей и приводящих к замене правящего класса другим классом, осталась в прошлом. В наше время актуальны революции иного типа - государственные перевороты, ведущие к смене правящих группировок и, соответственно, политического курса взявших власть элит. Подобный переворот и пытаются подготовить радикал-либералы, использовав массовое недовольство социальными результатами постсоветских реформ. Причем в данном случае они усматривают выход из создавшейся ситуации в восстановлении неолиберального курса 1990-х гг., от которого, по их убеждению, отошел путинский режим.

Не следует недооценивать политические возможности радикал-либеральной оппозиции. Во-первых, она тесно связана со структурами всех уровней государственной власти, поскольку практически все ее лидеры в свое время сами занимали влиятельные посты в этих структурах и до сих пор имеют там много единомышленников. Во-вторых, ее явно и скрытно поддерживает олигархический капитал, политически ориентируя и финансируя деятельность оппозиционных организаций. В-третьих, новейшие информационные и коммуникационные технологии позволяют этим организациям создавать сетевые структуры в целях координации протестных выступлений и манипуляции массовым сознанием. Кумулятивная реализация этих возможностей способна поставить режим в весьма уязвимое положение, вызвав дестабилизацию обстановки и понизив уровень доверия масс к власти и без того неустойчивой, поскольку она во многом зависит от внешнеполитических факторов, таких как крымский кон- 
сенсус, российско-украинские отношения, санкционные войны Запада, военная угроза со стороны Вашингтона и НАТО.

В данном контексте призрак новой революции в России обретает черты реальной геополитической угрозы. По иронии истории цитадель мирового империализма стала оплотом мировой революции, на этот раз либеральной. Всякие попытки ответвить ее в Россию можно адекватно осмыслить лишь в таком международном контексте.

\title{
Список литературы
}

Бердяев Н.А. 1990. Философия неравенства. М.: ИМА-пресс. 288 с.

Двадиать пять лет социальных трансформаций в оценках и суждениях россиян: опыт социологического анализа (отв. ред. М.К. Горшков, В.В. Петухов). 2018. М.: Весь Мир. 388 с.

Крауч К. 2012. Странная не-смерть неолиберализма. М.: Дело. 272 с.

Милюков П.Н. 1930. Суд над кадетскими «либералами». - Современные записки. № 41.

Попова А.В. 2006. Либерализм в России: особенности развития. - Право и государство: теория и практика. № 9. С. 135-141.

Российское общество и вызовы времени. Кн. 4 (под ред. М.К. Горшкова, В.В. Петухова). 2016. М.: Весь Мир. 400 с.

Свобода. Неравенство. Братство: Социологический портрет современной России (авт.-сост. Е.П. Добрынина; под общ. ред. М.К. Горшкова). 2007. М.: ИИК «Российская газета». 448 с.

Сергеев Д. 2013. Будущая либеральная революция. Альтернативы системе. Анархическое движение. - Автономное действие. 2013. Доступ: https://avtonom. org/author_columns/budushchaya-liberalnaya-revolyuciya-v-rossii проверено 13.03.2020).

Социальные неравенства и социальная политика в современной России (отв. ред. М.К. Горшков, Н.Е. Тихонова). 2008. М.: Наука. 423 с.

OGANIS'YAN Yuliy Stepanovich, Dr.Sci. (Hist.), Professor; Chief Research Scientist at the Sociological Institute - branch of the Federal Center of Theoretical and Applied Sociology, Russian Academy of Sciences (bld. 5, 24/35 Krzhizhanovskogo St, Moscow, Russia, 117218; dorunat@gmail.com)

\section{POST-SOVIET LIBERALISM: FROM REFORM TO REVOLUTION?}

\author{
Abstract. The author analyzes the phenomenon of radicalization of socio-political views of ideologists of post-Soviet \\ liberalism, who, appealing to the protest moods of the masses, form the idea of brewing a new - anti-Putin - revolution \\ in Russia. Based on the data of sociological studies, the author proves the inconsistency of their claims about the pre- \\ revolutionary situation in the country, allowing at the same time the possibility of destabilization of the socio-political situation \\ by combining radical-liberal ideas with a mass protest movement and external support for non-systemic opposition. \\ Keywords: liberal reformism, revolutionary situation, social inequality, non-systemic opposition, protest movement
}

